\title{
Potentiated clinoptilolite reduces signs and symptoms associated with veisalgia
}

This article was published in the following Dove Press journal:

Clinical and Experimental Gastroenterology

25 August 2015

Number of times this article has been viewed

\section{Justin John Gandy}

Ilze Laurens

Jacques Rene Snyman

Department of Pharmacology, School of Medicine, Faculty of Health Sciences, University of Pretoria, Pretoria, Gauteng, South Africa
Correspondence: Ilze Laurens Department of Pharmacology, University of Pretoria, Basic Medical Sciences Building, 6th floor, 9 Bophelo Road, Prinshof Campus, Pretoria, Republic of South Africa, I50 I

Tel +2782 4489153

Email ilze@dermav.co.za
Introduction: Abundant anecdotal evidence for products claiming to reduce veisalgia after alcohol overindulgence are available on the Internet and as many advertisements in journals. None of these claims are, however, substantiated by research. The aim of this research was to ascertain the validity of such claims for the substance Absorbatox ${ }^{\mathrm{TM}}$, a potentiated aluminosilicate (cation exchanger able to bind $\mathrm{NH}^{4+}$, histamine, and other positively charged ions) by investigating the signs and symptoms, as well as blood or breath alcohol levels, in healthy volunteers.

Methods: Blood or breath alcohol levels were measured in all volunteers in initial controlled experiments, and symptoms were scored on a diary card for gastrointestinal tract symptoms, as well as other symptoms such as headache and light sensitivity. Eighteen volunteers completed the initial blood alcohol study, which investigated the effect of Absorbatox ${ }^{\mathrm{TM}}$ on blood alcohol levels after fasting. The follow-up studies researched the effects of the symptoms and signs of alcohol overindulgence. The "night out" study was completed by ten volunteers in a typical controlled environment, which was followed by the real-life four-leg crossover study. In the crossover study, volunteers (number $=25$ completers) had to fill matching diary cards to containers of two placebo and two active drugs after a night out where they themselves decided on the container (color coded) to be used and the amount of alcohol to be consumed.

Results: Absorbatox ${ }^{\mathrm{TM}}$ had no effect on blood alcohol levels, but it significantly reduced the symptoms and signs of veisalgia by approximately $40 \%-50 \%$.

Conclusion: This research indicates that Absorbatox ${ }^{\mathrm{TM}}$ does not have an effect on blood- or breath-alcohol levels. Furthermore, treatment with Absorbatox ${ }^{\mathrm{TM}}$ resulted in an overall significant reduction in central nervous system and gastrointestinal tract symptoms associated with veisalgia, warranting further investigation.

Keywords: hangover, clinoptilolite, Absorbatox, alcohol

\section{Introduction}

Abundant anecdotal evidence for products claiming to reduce veisalgia - ie, to prevent or sober up after alcohol overindulgence - are available on the Internet and as many advertisements in journals. These claims are mostly unsubstantiated by research other than claims by "users" or "clients" of the purported products.

Veisalgia describes the sum of unpleasant physiological effects following the consumption of substances such as alcoholic beverages. The word originated from the Norwegian word "kveis" (meaning uneasiness after debauchery) and the Greek root "-algia" (meaning pain, grief). ${ }^{1}$ The most commonly reported characteristics of veisalgia ("hangover") include headache, nausea, sensitivity to light and noise, lethargy, dysphoria, and thirst. Alcohol overindulgence is a global phenomenon with a significant number of people suffering from the consequences - ie, hangover 
to addiction, the latter often associated with serious legal, social, and health sequelae. ${ }^{2}$

Ethanol $(\mathrm{EtOH})$ in the blood affects the brain and other tissues until it is metabolized by the liver through oxidation, detoxifying the substance, and rendering it harmless to tissues and organs. A small amount of EtOH is excreted unchanged via the lungs and urine. ${ }^{3,4}$ The rate at which the liver can metabolize EtOH depends on the amount of alcohol dehydrogenase. ${ }^{3}$ This is the enzyme responsible for catalyzing the oxidation reaction, which detoxifies the $\mathrm{EtOH}$. If the rate of EtOH consumption surpasses the rate of EtOH metabolism, it results in an excessive increase in blood alcohol concentration due to zero-order kinetics.

Factors that could influence the rate of EtOH absorption and metabolism during such alcohol studies, include food consumption, as well as the sex of the individual. The presence of food and also the type of food present in the gastrointestinal tract (GIT) influence EtOH absorption. ${ }^{4,5}$ The rate at which EtOH is absorbed in the GIT depends on the rate at which the stomach empties its contents into the small intestine (timing after consumption), where most of the consumed $\mathrm{EtOH}$ is then absorbed. Foods that are high in dietary fat will delay emptying of the stomach and will therefore lower the rate at which EtOH is absorbed. Furthermore, research has shown that that subjects consuming alcohol with food containing protein, carbohydrates, and fat absorbed the alcohol three times slower than subjects ingesting alcohol on an empty stomach. ${ }^{6}$

\section{Absorbatox ${ }^{\mathrm{TM}}$}

Absorbatox $^{\mathrm{TM}}$ falls under a family of natural and/or synthetic hydrated aluminosilicates. These are molecules with welldefined, microporous, crystalline structures, which carry an excessive negative charge, usually compensated for by cations. ${ }^{7}$ Void spaces within the frameworks are capable of hosting cations, water, or other organic molecules that, in turn, can be selectively exchanged for other species. ${ }^{8}$ The porous structure allows hydrated aluminosilicates to have a unique "molecular sieving" ability. ${ }^{9}$

Absorbatox $^{\mathrm{TM}}$ is mined in a specific geographical region where the deposits are known to be contaminant free. Absorbatox $^{\mathrm{TM}}$ is an authigenic mineral or sedimentary rock, which has been processed and potentiated via a patented process to exhibit a pronounced negative molecular charge. Many known processes to potentiate clinoptilolites have been described, and may include saturation in brine. ${ }^{10-14}$

Absorbatox $^{\mathrm{TM}}$ is a mineral (clinoptilolite) with the simplified formula $(\mathrm{Na}, \mathrm{K})_{6} \mathrm{Si}_{30} \mathrm{Al}_{6} \mathrm{O}_{72}-\mathrm{nH}_{2} \mathrm{O}$ (hydrated clinoptilolite), and it is one of the many zeolites most commonly found in sedimentary rock. ${ }^{15,16}$ It belongs to the aluminosilicate species.
There are 108 different zeolites. Absorbatox ${ }^{\mathrm{TM}}$ is a specific zeolite, with a particular Mohs hardness and cation exchange capability. Zeolites are hydrated natural microporous crystals with well-defined structures containing $\mathrm{AlO}_{4}$ and $\mathrm{SiO}_{4}$ tetrahedra linked through the common oxygen atoms. Most common natural zeolites are formed by alteration of glass-rich volcanic rocks (tuff) with fresh water in playa lakes or by seawater. The structures of zeolites consist of three-dimensional frameworks of $\mathrm{SiO}_{4}$ and $\mathrm{AlO}_{4}$ tetrahedra. The aluminum ion is small enough to occupy the position in the center of the tetrahedron of four oxygen atoms and the isomorphous replacement of $\mathrm{Si}^{4+}$ by $\mathrm{Al}^{3+}$ produces a negative charge in the lattice. The net-negative charge is balanced by the exchangeable cation (sodium, potassium, or calcium). It is also known that silicates and aluminosilicates possess biological activity, either positive or negative. Well-defined structures and catalytic activity make aluminosilicates an attractive model system for protein and enzyme mimetics. Natural zeolites are characterized by the ability to lose and gain water reversibly and to exchange constituent cations (positively charged particles) without a major change of structure.

When this "molecular sieving" ability is used in combination with hydrophobic principles to produce a physiologically inert hydrophobic molecular sieve material with a pore size that may permit the absorption of the EtOH molecule into the structure, it can be speculated that this substance would absorb a percentage of consumed EtOH before it can be absorbed by the GIT, which might result in lowered blood alcohol levels or slow absorption, as well as veisalgia symptom reduction. ${ }^{17}$

Furthermore, due to their unique physical attributes, aluminosilicates are able to absorb biological active amines such as histamine. ${ }^{18}$ It is known that increased plasma levels of serotonin and histamine due to alcohol consumption have been implicated in the pathogenesis of headaches. ${ }^{19-21}$

There are many purported claims for over-the-counter products to reduce alcohol absorption and/or to "sober up". The aim of this study was to test Absorbatox ${ }^{\mathrm{TM}}$ in this regard-ie, will it assist in "sobering up" the individual using the product when taking copious amounts of alcohol? To achieve this, the effects of Absorbatox ${ }^{\mathrm{TM}}$ on blood and breath alcohol levels, as well as the signs and symptoms of veisalgia, will be studied. Three different studies featuring treatment with Absorbatox ${ }^{\mathrm{TM}}$ were constructed to test whether it 1) decreases or "slows" blood alcohol concentrations when fasting; 2) decreases expirated alcohol when taken with food; and 3) results in a decreased severity of veisalgia-associated symptoms (ie, GIT-related symptoms such as thirst, nausea, vomiting, and bowel irritation, and central nervous system [CNS]-related symptoms such as fatigue, headache, light- and sound sensitivity, irritability, and alertness). 


\section{Materials and methods}

Three separate studies were conducted. The inclusion criteria for all three studies described in this section were healthy male or female volunteers over the age of 18 years who drink on social occasions.

Volunteers were excluded if they had a history of drug or alcohol abuse, do not drink at all, suffered from hypertension $(140 / 90 \mathrm{mmHg})$ or hypotension $(90 / 60 \mathrm{mmHg})$, and/or had diabetes mellitus type 1 or 2 , or any other systemic disease at the time of the study. Approval was obtained from the Ethics Committee of the University of Pretoria. All volunteers provided written informed consent to participate in the study.

\section{Effect of Absorbatox ${ }^{\mathrm{TM}}$ on alcohol absorption while fasting: determination of peak blood alcohol concentrations}

In this crossover study, volunteers that met the aforementioned inclusion/exclusion criteria were randomized into one of two groups. Each group consisted of nine subjects per group, amounting to a total of 18 volunteers who served as their own controls. One group received Absorbatox ${ }^{\mathrm{TM}}$ and alcohol (40\% EtOH; Smirnoff vodka; Diageo plc, London, UK), while the other group received $\mathrm{EtOH}$ alone. After a washout period of 72 hours, the treatment was switched. The group that previously received Absorbatox ${ }^{\mathrm{TM}}$ and $\mathrm{EtOH}$ were now given alcohol alone, and vice versa. Each person consumed $22 \mathrm{~mL}$ of EtOH over a period of 10 minutes, after which 11 $\mathrm{mL}$ of EtOH was consumed 20 minutes later (amounting to a total of three drinks [33 mL of EtOH] over a 30-minute period). In the group that received Absorbatox ${ }^{\mathrm{TM}}$ and $\mathrm{EtOH}$, two Absorbatox ${ }^{\mathrm{TM}} 2.8 \mathrm{D}$ capsules (1.5 g in total) were given before alcohol consumption. Additionally, two capsules (1.5 $\mathrm{g}$ in total) were given after 1 and 2 hours of alcohol consumption, respectively, thus totaling six capsules ( $4.5 \mathrm{~g}$ in total). Blood alcohol levels were measured before alcohol consumption (time $=0$ ), immediately after alcohol consumption (time $=30$ minutes), and at time $=60,90,120$, and 240 minutes.

Statistical analysis

All data were analyzed by means of a two-tailed paired $t$-test with a $95 \%$ confidence interval. The data were considered significant at a $P$-value $\leq 0.05$.

\section{Effect of Absorbatox ${ }^{\mathrm{TM}}$ on alcohol absorption with food: determination of expirated alcohol and severity of veisalgia-associated symptoms}

In this double-blind, placebo-controlled, crossover study, volunteers that met the aforementioned inclusion/exclusion criteria were randomized into one of two groups. Each group consisted of five subjects per group, amounting to a total of ten volunteers who served as their own controls. One group received Absorbatox ${ }^{\mathrm{TM}}$, food (standardized meal each time), and alcohol (EtOH), while the other group received placebo, food, and $\mathrm{EtOH}$. Volunteers were allowed to select their own drink; however, the volume and type had to be the same each time. This was noted and recorded against time to allow for matching after crossover. After a washout period of $>72$ hours, the treatment was switched. The group that previously received Absorbatox ${ }^{\mathrm{TM}}$ was now given placebo, and vice versa. A participant received his/her drink of choice in a social environment mimicking real life, amounting to an average of at least two drinks (a total of $20 \mathrm{~mL}$ of EtOH) every 1 hour over a 3-hour period, after which three Absorbatox ${ }^{\mathrm{TM}} 2.8 \mathrm{D}$ capsules (a total of $2.25 \mathrm{~g}$ ) were administered. All alcohol, food intake, and times of consumption were documented and repeated in exactly the same manner when the individual returned for the crossover phase. Breath alcohol levels were determined using a breathalyzer (Drägerwerk AG, Luebeck, Germany) at 30 and 60 minutes after consumption of three Absorbatox ${ }^{\mathrm{TM}} 2.8 \mathrm{D}$ capsules (a total of $2.25 \mathrm{~g}$ ). CNS and GIT signs and symptoms were recorded the following morning on a standardized score sheet on a scale of 1-10 (1= sign/symptom not experienced, and $10=\mathrm{sign} / \mathrm{symptom}$ is severe). GIT-related symptoms included thirst, nausea, vomiting, and bowel irritation and CNS (cognitive) symptoms included fatigue, headache, light and sound sensitivity, irritability, and alertness.

Each symptom was scored on a scale of 1-10 (1= sign/ symptom not experienced, and $10=$ sign/symptom is severe). In the cognitive domain, six symptoms were assessed, thus resulting in a possible maximum score of 60 per patient. In the GIT domain, four symptoms were assessed, thus resulting in a possible maximum score of 40 per patient The results are indicated as the mean GIT and CNS scores of patients per group (inclusive of all four previously mentioned GIT symptoms and all six previously mentioned CNS symptoms that were assessed).

\section{Statistical analysis}

Statistical analysis was done using a Wilcoxon signed-rank test. The data were considered significant at a $P$-value $\leq 0.05$.

\section{Confirmation of Absorbatox ${ }^{\mathrm{TM}}$-induced reduction of veisalgia-associated symptoms in a real-life setting}

In this randomized, double-blind, placebo-controlled crossover study, 42 participants that met the aforementioned inclusion/ exclusion criteria were enrolled into this "real-life" study, of 
which only 25 volunteers successfully completed all arms of the study within the scheduled time. Each volunteer received four colored containers (red, blue, yellow, and green), of which two contained placebo capsules and two contained active capsules (Absorbatox ${ }^{\text {TM }}$ 2.8 D). Participants did not know which contained the active capsules and they were free to select any one for a single social event (normal social behavior of the participant). The dosage of Absorbatox ${ }^{\mathrm{TM}} 2.8 \mathrm{D}$ or placebo taken in this study was $2.25 \mathrm{~g}$ (three capsules $\times 750 \mathrm{mg}$ each) at the end of a night of "overindulgence". Volunteers completed the corresponding color-coded symptom score sheet (1-10 scale) $(1=$ symptom not experienced, and $10=$ symptom is severe) the following morning. GIT-related symptoms included thirst, nausea, vomiting, and bowel irritation, and CNS (cognitive) symptoms included fatigue, headache, lightand sound sensitivity, irritability, and alertness.

\section{Statistical analysis}

Statistical analysis was done using a Wilcoxon signed-rank test. The data were considered significant at a $P$-value $\leq 0.05$.

\section{Results}

\section{Determination of peak blood alcohol concentrations in fasting subjects treated with $4.5 \mathrm{~g}$ of Absorbatox ${ }^{\mathrm{TM}}$}

It was proven that there were no significant differences in the blood alcohol concentrations at the different time intervals (time $=0,30,60,90,120$, or 240 minutes) between the groups taking Absorbatox ${ }^{\mathrm{TM}}$ Vs the placebo group (Figure 1). Absorbatox $^{\mathrm{TM}}$ did not reduce the blood alcohol concentrations of participants who ingested three drinks $(33 \mathrm{~mL}$ EtOH) over a 30-minute period. There was also no delay in the absorption, reflecting a normal gastric emptying time (motility not affected).

\section{Determination of expirated alcohol and severity of veisalgia-associated symptoms in fed subjects}

Pertaining to the concentrations of exhaled alcohol, no significant difference was detected between the groups that received Absorbatox ${ }^{\mathrm{TM}}$ when compared to the groups that received placebo (Figure 2). Absorbatox ${ }^{\mathrm{TM}}$ made no difference to breath alcohol concentrations that were reached after an evening of standardized free drinking and eating.

However, the results showed that Absorbatox ${ }^{\mathrm{TM}}$ results in a significant decrease in veisalgia-associated symptoms when comparing the treated groups with the placebo groups, respectively (Table 1). Absorbatox ${ }^{\mathrm{TM}}$ significantly $(P=0.01)$ reduced both the GIT and CNS symptoms. Absorbatox ${ }^{\mathrm{TM}}$ resulted in a $50 \%$ reduction in GIT symptoms $(P=0.01)$ and a $32 \%$ reduction in the CNS symptoms $(P=0.01)$ of veisalgia.

\section{Confirmation of Absorbatox ${ }^{\mathrm{TM}}$-induced reduction of veisalgia-associated symptoms in subjects with normal social behavior of consuming alcohol}

The symptom score sheets of 25 volunteers were analyzed in this four-time crossover, double-blind study. The results are summarized in Tables 1 and 2. The results are indicated as the mean GIT and CNS scores of patients per group. These results indicate that the use of Absorbatox ${ }^{\mathrm{TM}}$ translates into a significant $(P<0.0001)$ decrease of veisalgia-associated symptoms when comparing the treated groups with the placebo groups, respectively. Absorbatox ${ }^{\mathrm{TM}}$ resulted in a $55 \%$ reduction in

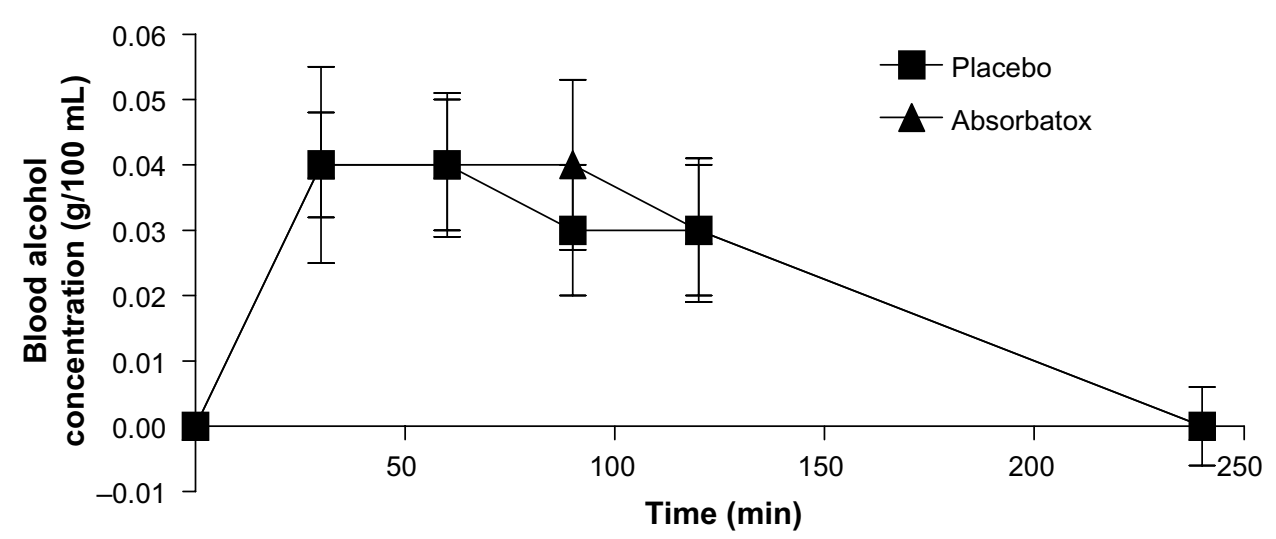

Figure I Patients' mean blood alcohol concentration from study A.

Notes: No significant difference in blood alcohol concentrations at different time intervals were obtained between the group taking Absorbatox ${ }^{\mathrm{TM}}$ versus those in the placebo group. Study A is the effect of Absorbatox ${ }^{\mathrm{TM}}$ on alcohol absorption while fasting: determination of peak blood alcohol concentrations.

Abbreviation: min, minutes. 


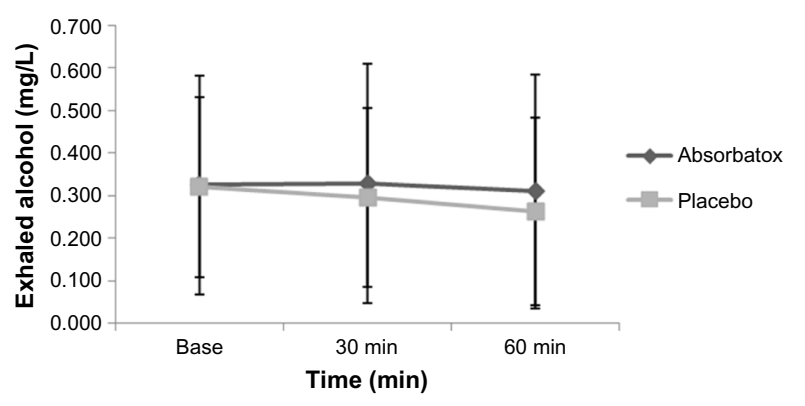

Figure 2 Patients' mean exhaled alcohol concentrations from study B.

Notes: No significant difference in the mean exhaled alcohol concentrations between the groups that received Absorbatox ${ }^{\mathrm{TM}}$ when compared to the groups that received placebo was observed. Study B is the effect of Absorbatox ${ }^{\mathrm{TM}}$ on alcohol absorption with food: determination of expirated alcohol and severity of veisalgiaassociated symptoms - controlled setting.

Abbreviation: min, minutes.

GIT symptoms $(P=0.001)$ and a $43 \%$ reduction in the CNS symptoms $(P=0.001)$ of veisalgia.

\section{Discussion and conclusion}

Alcohol overindulgence is associated with gastrointestinal disturbances such as upper abdominal pain, nausea, and vomiting, and CNS symptoms including headache, irritability, dizziness. ${ }^{22}$ These GIT symptoms possibly manifest due to direct irritation of the stomach lining (gastritis), increased gastric acid and pepsin secretion, and pancreatic and other intestinal secretions. ${ }^{22}$ Headaches associated with hangovers have been attributed, in some part, due to the effect of alcohol on neurotransmitters and the release of autacoid hormones such as histamine, serotonin, and prostaglandins, which have been implicated in the pathogenesis of headaches. ${ }^{23}$

This research indicates that Absorbatox ${ }^{\mathrm{TM}}$ does not have an effect on blood or breath alcohol levels. Further results demonstrate that treatment with Absorbatox ${ }^{\mathrm{TM}}$ results in an overall significant reduction in CNS and GIT symptoms associated with veisalgia. The exact mechanism of action is not elucidated in this study, but the reported effects on heartburn and gastritis $^{24}$ may indicate that Absorbatox ${ }^{\mathrm{TM}}$ possibly binds the offending $\mathrm{H}^{+}$ions, pepsin, and biologically active amines, such as histamine and serotonin. These studies also acted as dose-finding experiments in that the first group received $4.5 \mathrm{~g}$ each, the participants in the second study received $2.25 \mathrm{~g}$ each, and those in the confirmation study also only received $2.25 \mathrm{~g}$ each, clearly demonstrating the capacity of the manipulated substance in adsorbing the active moieties in the GIT. The initial hypothesis of alcohol "binding" by the sieve is therefore rejected. The lower dose was selected, as this was the dose with anecdotal claims; the higher dosages were also used to demonstrate any mopping effect of alcohol, if at all possible. This further strengthens the argument for the specific binding of active substances, such as histamine and other biologically active amines (in in vitro experiments), as opposed to nonspecific changes in $\mathrm{pH}$ and gastric enzymes. The dosages used for the treatment of gastroesophageal reflux disease and stomach protection against nonsteroidal anti-inflammatory drugs were also similar to the low range - ie, 750-1,500 mg per dose - and demonstrated efficacy. ${ }^{24}$

Unpacking the different score charts, it is obvious that the benefits are driven by specific symptoms being significantly reduced. These were in the cognitive domain: headache; light and sound sensitivity; and, to a lesser extent, irritability. Alertness was not at all influenced, demonstrating that the effect of alcohol in suppressing the CNS remained intact. This strengthens the hypothesis that Absorbatox ${ }^{\mathrm{TM}}$ binds to and mops up products such as histamine and serotonin after direct insult to the GIT, with no effect on the true CNS effects of alcohol. The GIT domain was also not uniformly affected,

Table I Cognitive domain results, as documented by patients the morning after ingesting alcohol on a six-symptom score sheet on a scale of $\mathrm{I}-10$ ( $\mathrm{I}=$ minimum severity; $10=$ maximum severity)

\begin{tabular}{|c|c|c|c|c|c|c|c|}
\hline \multirow{2}{*}{$\begin{array}{l}\text { Clinical } \\
\text { symptom }\end{array}$} & \multirow{2}{*}{$\begin{array}{l}\text { Unit of } \\
\text { measurement }\end{array}$} & \multicolumn{3}{|c|}{ Study B $(n=10)$} & \multicolumn{3}{|c|}{ Study C $(n=50)$} \\
\hline & & $\begin{array}{l}\text { Placebo } \\
(n=10)\end{array}$ & $\begin{array}{l}\text { Absorbatox }^{\mathrm{TM}} \\
(\mathrm{n}=\mid 0)\end{array}$ & $P$-value & $\begin{array}{l}\text { Placebo } \\
(n=50)\end{array}$ & $\begin{array}{l}\text { Absorbatox }^{\mathrm{TM}} \\
(\mathrm{n}=50)\end{array}$ & P-value \\
\hline Fatigue & Mean score \pm SEM & $5.45 \pm 2.29$ & $3.80 \pm 2.53$ & 0.4 & $3.52 \pm 0.15$ & $1.66 \pm 0.11$ & 0.02 \\
\hline Headache & & $2.70 \pm 2.98$ & $1.40 \pm 0.70$ & 0.0001 & $3.46 \pm 0.19$ & $1.58 \pm 0.11$ & 0.0001 \\
\hline Light sensitivity & & $3.40 \pm 2.17$ & $2.25 \pm 1.23$ & 0.05 & $2.90 \pm 0.19$ & $1.8 \pm 0.14$ & 0.02 \\
\hline Sound sensitivity & & $1.90 \pm 1.20$ & $1.80 \pm 1.32$ & 0.4 & $2.90 \pm 0.18$ & $1.62 \pm 0.13$ & 0.008 \\
\hline Irritability & & $3.80 \pm 3.05$ & $2.40 \pm 1.51$ & 0.02 & $3.80 \pm 0.16$ & $1.88 \pm 0.11$ & 0.007 \\
\hline Alertness & & $6.10 \pm 1.85$ & $5.30 \pm 2.63$ & 0.16 & $2.62 \pm 0.16$ & $2.42 \pm 0.17$ & 0.4 \\
\hline $\begin{array}{l}\text { Cognitive domain } \\
\text { summation }\end{array}$ & $\begin{array}{l}\text { Score summation } \\
\text { of six CNS } \\
\text { symptoms }\end{array}$ & $23.35 \pm 9.15$ & $16.95 \pm 5.52$ & 0.01 & $38.40 \pm 6.90$ & $21.92 \pm 3.65$ & 0.0001 \\
\hline
\end{tabular}

Notes: Study B is the effect of Absorbatox ${ }^{\mathrm{TM}}$ on alcohol absorption with food: determination of expirated alcohol and severity of veisalgia-associated symptoms - controlled setting. Study $C$ is the effect of Absorbatox ${ }^{\mathrm{TM}}$ on alcohol absorption with food: determination of expirated alcohol and severity of veisalgia-associated symptoms - social setting. Abbreviations: $n$, number; SEM, standard error of the mean; CNS, central nervous system. 
Table 2 GIT domain results, as documented by patients the morning after ingesting alcohol on a four-symptom score sheet on a scale of $\mathrm{I}-10$ ( $\mathrm{I}=$ minimum severity; $\mathrm{I} 0=$ maximum severity)

\begin{tabular}{|c|c|c|c|c|c|c|c|}
\hline \multirow{2}{*}{$\begin{array}{l}\text { Clinical } \\
\text { symptom }\end{array}$} & \multirow{2}{*}{$\begin{array}{l}\text { Unit of } \\
\text { measurement }\end{array}$} & \multicolumn{3}{|c|}{ Study B $(n=10)$} & \multicolumn{3}{|c|}{ Study C $(n=50)$} \\
\hline & & $\begin{array}{l}\text { Placebo } \\
(n=10)\end{array}$ & $\begin{array}{l}\text { Absorbatox }^{\mathrm{TM}} \\
(\mathrm{n}=10)\end{array}$ & $P$-value & $\begin{array}{l}\text { Placebo } \\
(n=50)\end{array}$ & $\begin{array}{l}\text { Absorbatox }{ }^{\mathrm{TM}} \\
(\mathrm{n}=50)\end{array}$ & $P$-value \\
\hline Thirst & Mean score \pm SEM & $4.40 \pm 2.17$ & $3.10 \pm 1.91$ & 0.4 & $3.80 \pm 0.13$ & $1.74 \pm 0.12$ & 0.2 \\
\hline Nausea & & $2.20 \pm 1.81$ & $1.00 \pm 0.00$ & 0.05 & $2.94 \pm 0.21$ & $1.70 \pm 0.13$ & 0.0006 \\
\hline Vomiting & & $1.70 \pm 2.21$ & $1.00 \pm 0.00$ & 0.05 & $3.10 \pm 0.19$ & $1.40 \pm 0.11$ & 0.0003 \\
\hline Bowel irritation & & $2.95 \pm 1.83$ & $1.60 \pm 1.08$ & 0.06 & $3.06 \pm 0.21$ & $1.88 \pm 0.21$ & 0.13 \\
\hline $\begin{array}{l}\text { GIT domain } \\
\text { summation }\end{array}$ & $\begin{array}{l}\text { Score summation of } \\
\text { four GIT symptoms }\end{array}$ & $11.25 \pm 6.56$ & $6.70 \pm 2.40$ & 0.01 & $25.80 \pm 5.38$ & $11.56 \pm 3.58$ & 0.001 \\
\hline
\end{tabular}

Notes: Study B is the effect of Absorbatox ${ }^{\mathrm{TM}}$ on alcohol absorption with food: determination of expirated alcohol and severity of veisalgia-associated symptoms - controlled setting. Study $C$ is the effect of Absorbatox ${ }^{\mathrm{TM}}$ on alcohol absorption with food: determination of expirated alcohol and severity of veisalgia-associated symptoms - social setting. Abbreviations: GIT, gastrointestinal tract; $n$, number; SEM, standard error of the mean.

and the symptoms here also related to afferent stimulation of the vagus nerve (nausea and vomiting), which was more inhibited than in those symptoms not related to direct effects and stimulation via autocrine transmitter release in the GIT. Thirst was not affected at all, and this is understandable as thirst is related to absolute or relative dehydration due to the increased diuresis driven by the alcohol ingested.

\section{Conclusion}

Further evaluation is warranted by the outcomes of these studies. Absorbatox ${ }^{\mathrm{TM}}$ is a nonabsorbable substance with benefits in preventing and reducing veisalgia symptoms without influencing the absorption of alcohol. The possible legal implications of alcohol consumption thus remain.

\section{Disclosure}

JR Snyman is a minor shareholder in Absorbatox Pty Ltd. The authors report no other conflicts of interest in this work.

\section{References}

1. Wiese JG, Shlipak MG, Browner WS. The alcohol hangover. Ann Intern Med. 2000;132(11):897-902.

2. Perkins HW. Surveying the damage: a review of research on consequences of alcohol misuse in college populations. J Stud Alcohol Suppl. 2002;(14):91-100.

3. Bosron WF, Ehrig T, Li TK. Genetic factors in alcohol metabolism and alcoholism. Semin Liver Dis. 1993;13(2):126-135.

4. Wallgren H, Barry H III. Actions of Alcohol, Vol 1: Biochemical, Physiological, and Psychological Aspects. Amsterdam, the Netherlands: Elsevier; 1970.

5. Fraser AG, Rosalki SB, Gamble GD, Pounder RE. Inter-individual and intra-individual variability of ethanol concentration-time profiles: comparison of ethanol ingestion before or after an evening meal. $\mathrm{Br} J$ Clin Pharmacol. 1995;40(4):387-392.

6. Jones AW, Jönsson KA. Food-induced lowering of blood-ethanol profiles and increased rate of elimination immediately after a meal. J Forensic Sci. 1994;39(4):1084-1093.

7. Seetharam G, Saville BA. L-DOPA production from tyrosine immobilized on zeolite. Enzyme Microb Technol. 2002;31(6):747-753.
8. Thom DC, Davies JE, Santerre JP, Friedman S. The hemolytic and cytotoxic properties of a zeolite-containing root filling material in vitro. Oral Surg Oral Med Oral Pathol Oral Radiol Endod. 2003;95(1): 101-108.

9. Dyer A, Morgan S, Wells P, Williams C. The use of zeolites as slow release anthelmintic carriers. J Helminthol. 2000;74(2):137-141.

10. Ames LL. Zeolite removal of ammonium ions from agricultural wastewaters. In: Proceedings of the 13th Pacific Northwest Industrial Waste Conference. Pullman, WA: Washington State University; 1967: $135-152$.

11. Mumpton FA. Commercial uses of natural zeolites. In: Lefond SJ, editor. Industrial Minerals and Rocks. New York, NY: The American Institute of Mining, Metallurgical, and Petroleum Engineers; 1975:1262-1274.

12. Mumpton FA. Natural zeolites: a new industrial mineral commodity. In: Sand LB, Mumpton FA, editors. Natural Zeolites: Occurrences, Properties, Uses. Oxford, UK: Pergamon Press; 1978:3-27.

13. Hedström A. Ion exchange of ammonium in zeolites: a literature review. Journal of Environmental Engineering. 2001;127(8):673-681.

14. Rahmani AR, Samadi MT, Ehsani HR. Investigation of clinoptilolite natural zeolite regeneration by air stripping followed by ion exchange for removal of ammonium from aqueous solutions. Iranian J Environ Health Sci Eng. 2009;6(3):167-172.

15. Bowman RS, Sullivan EJ, Li Z. Uptake of cations, anions, and nonpolar organic molecules by surfactant-modified clinoptilolite-rich tuff. In: Colella C, Mumpton FA, editors. Natural zeolites for the third millenium. 2000:287-297.

16. Mumpton FA, Fishman PH. The application of natural zeolites in animal science and aquaculture. J Anim Sci. 1977;45(5):1188-1203.

17. Wren JJ. Adsorbent composition: Google Patents US4877601 A; October 31, 1989.

18. Johnson HH Jr. A microchemical method for the determination of histamine; its application to skin biopsies. AMA Arch Derm. 1955;72(4): 307-312.

19. Kaufman HS. Red wine headache. Lancet. 1988;1(8592):992-993.

20. Littlewood JT, Gibb C, Glover V, Sandler M, Davies PT, Rose FC. Red wine as a cause of migraine. Lancet. 1988;1(8585):558-559.

21. Panconesi A. Alcohol and migraine: trigger factor, consumption, mechanisms. A review. J Headache Pain. 2008;9(1):19-27.

22. Swift R, Davidson D. Alcohol hangover: mechanisms and mediators. Alcohol Health Res World. 1998;22(1):54-60.

23. Parantainen J. Prostaglandins in alcohol intolerance and hangover. Drug Alcohol Depend. 1983;11(3-4):239-248.

24. Potgieter W, Samuels CS, Snyman JR. Potentiated clinoptilolite: artificially enhanced aluminosilicate reduces symptoms associated with endoscopically negative gastroesophageal reflux disease and nonsteroidal anti-inflammatory drug induced gastritis. Clin Exp Gastroenterol. 2014;7:215-220. 
Clinical and Experimental Gastroenterology

Dovepress

\section{Publish your work in this journal}

Clinical and Experimental Gastroenterology is an international, peerreviewed, open access journal, publishing all aspects of gastroenterology in the clinic and laboratory, including: Pathology, pathophysiology of gastrointestinal disease; Investigation and treatment of gastointestinal disease; Pharmacology of drugs used in the alimentary tract;

Immunology/genetics/genomics related to gastrointestinal disease. This journal is indexed on CAS. The manuscript management system is completely online and includes a very quick and fair peer-review system. Visit http://www.dovepress.com/testimonials.php to read real quotes from published authors.

Submit your manuscript here: http://www.dovepress.com/clinical-and-experimental-gastroenterology-journal 